\title{
AE317 \\ Nonstructural Partitions and Floor Vibration Serviceability
}

\author{
Austin Devin ${ }^{1}$, Paul J. Fanning ${ }^{2}$, Aleksandar Pavic ${ }^{3}$ \\ ${ }^{1}$ School of Civil, Structural \& Environmental Engineering, Newstead, University College Dublin, Belfield, Dublin 4, \\ Ireland. \\ ${ }^{2}$ School of Civil, Structural \& Environmental Engineering, Newstead, University College Dublin, Belfield, Dublin 4, \\ Ireland. \\ ${ }^{3}$ College of Engineering, Mathematics \& Physical Sciences, University of Exeter, Exeter, Devon, EX4, United \\ Kingdom.
}

\begin{abstract}
Non-structural vertical partitions and cladding can have a significant effect on the vibration serviceability of floor systems. A typical modern office building, consisting of steel-concrete composite floor systems, was created to investigate the potential beneficial effects of integrating non-structural partitions into structural floor systems to reduce floor vibrations due to walking excitation. Two models of this building were presented, one to represent the completed building with an open-plan layout and another with partitions added in a beneficial pattern to enhance the floor's vibration performance. The addition of non-structural partitions successfully reduced floor accelerations due to walking excitation and helped the floor to satisfy the vibration serviceability criterion for office floors.
\end{abstract}

The potential of vertical full-height non-structural partitions and cladding to transmit vibrations between floors was also investigated. A vibration transmission simulation was conducted on the 
Finite Element (FE) model to quantify vibration transmission between floors through the structural frame and non-structural vertical partitions and cladding. The results were then compared with experimental results previously recorded on the floors of a real-life Charles Institute building in Dublin featuring the same type of partitions but different structural frame. It was concluded that both the FE model and real-life building featuring structural elements and full-height partitions have the potential to transmit significant level of vibrations between two adjacent floors.

The results presented in this study will be of interest to design engineers and researchers in the area of vibration serviceability of floor systems, as it highlights the potential of non-structural elements to reduce the floor vibration response to acceptable levels to transmit vibrations between floors.

\section{Introduction}

Vibration serviceability of floor systems can be a significant issue in buildings. The trend towards slender floors and longer spans exacerbate this issue due to their lower natural frequencies and damping ratios, thus increasing the possibility of the presence of annoying floor vibrations that could affect the comfort of building occupants. Research into mitigation of these unwanted vibrations has led to a number of potential techniques to attenuate excessive vibrations such as active and passive control and viscoelastic screed layers.

Comprehensive knowledge of the dynamic response of structural systems is required for a design that satisfies the demands of vibration serviceability. Traditional reinforced concrete floor systems have had an excellent track record in this regard (Pavic et al. 2001), due to their high 
stiffness and damping ratio. However, the trend towards increased floor spans and slenderness, caused by a demand for faster construction times and open-plan floor layouts, has increased the construction of composite steel-concrete and post-tensioned concrete floor systems. Such floors are more likely to exhibit vibration serviceability issues, if not explicitly considered, due to their slenderness and lower energy dissipation capability (Pavic et al. 2002; Pavic et al. 2007; Nyawako et al. 2013). Slender floors require careful consideration of the overall dynamic behaviour of the building, and innovative methods have been utilised to satisfy vibration serviceability demands and increase the energy dissipation capability of such structures; these include increasing structural stiffness or reducing mass, passive and active vibration control (Yang \& Soong 1988; Soong \& Costantinou 1994; Alkhatib \& Golnaraghi 2003; Datta 2003) and viscoelastic dampers (Saidi et al. 2011).

Increasing stiffness or reducing mass will increase the natural frequency of the structure, thus reducing the possibility of resonance between the structure's natural frequency and the frequency range of the excitation source, typically walking humans in the case of floors (Brownjohn \& Pavic 2006). The use of passive and active control, which was first highlighted as a potential method to minimise earthquake damage in seismic regions (Crosby et al. 1974; Dyke \& Spencer 1996; Choi \& Cho 2004), has also been investigated as a potential solution to reduce troublesome floor vibrations. Hudson et al. (2011; 2013), Chen et al. (2012) and Symans and Constantinou (1999) demonstrated the potential of utilising active vibration control to minimise floor vibrations. It has also been illustrated that non-structural elements can have significant effects on the dynamic response of floor systems of buildings; evidence of such effects was observed in determining the dynamic parameters of both slender floor systems (Reynolds 2000; Miskovic et al. 2009) and traditional concrete floor systems as detailed by Devin \& Fanning 
(2012). However, it still remains difficult to predict accurately the contribution of non-structural elements at the design stage of buildings.

Typically, a bare frame finite element (FE) model analysed during the design of a building, neglects any contribution of non-structural elements to a structure's dynamic response. The exclusion of non-structural elements causes discrepancies between a numerical model of a building and its actual structural response, as highlighted by Ventura et al. (2002), Pan et al. (2006) and Miskovic et al. (2009). Such discrepancies can lead to unexpected effects on vibration serviceability of floors and their response to dynamic loading. For this reason, whenever possible, dynamic testing is increasingly utilised for the identification of a structure's actual in-service modal properties, which, in turn, are used to update the initial FE model to represent accurately the real structural response. Traditional experimental modal analysis and output-only techniques are the most popular methods for determining these dynamic parameters from in-situ tests on real in-service civil engineering structures. Both of these methods have been used for analysing the behaviour of non-structural elements and their contribution to a structure's dynamic response. Miskovic et al. (2009) analysed the effect of full-height partitions using forced vibration testing. Ventura et al. (2002) used ambient vibration results to update a FE model of a building including non-structural elements. Li et al. (2002) highlighted that measured natural frequencies of a 79 storey building were higher than those calculated from the FE model, concluding that this difference was due to the presence of non-structural elements.

In this paper, a case study is presented which investigates the potential of internal partitions to aid in the attenuation of vertical floor vibrations. Steel-concrete composite floor systems, with low natural frequencies and damping ratios, are known to be susceptible to excessive floor vibrations (Pavic et al. 2007; Díaz et al. 2012; Nyawako et al. 2013). The effect non-structural 
elements have on the dynamic response and vibration serviceability is examined by including the representation of non-structural elements developed from previous experimental testing (Devin 2013). The aim of this case study was to illustrate how an efficient layout of non-structural elements can have a beneficial effect on the vibration serviceability of floor systems. Additionally, the potential of non-structural elements to transmit vibration to the floor above and/or below is demonstrated and the implications of this behaviour are highlighted.

\section{Case Study Building}

To investigate the potential of non-structural partitions to attenuate excessive floor vibration, a model of a typical multi-storey composite steel-concrete building was developed in ANSYS according to Eurocode 4 (STN 1994). The case study building is reallistic aa it consists of a four storey steel-concrete composite structural system, typically used in modern office buildings. This typical slender floor system was chosen to investigate its vibration serviceability, dynamic response and to evaluate the effect non-structural partitions can have on such a structure. The floor system consisted of a $150 \mathrm{~mm}$ deep steel profiled composite slab supported on secondary beams spanning $6 \mathrm{~m}$ that were supported in turn on primary beams spanning $12 \mathrm{~m}$. For the model building, a typical floor structural layout, ideantical for all four floor levels, is shown in Figure 1.

Steel-concrete composite floor systems have been known to be susceptible to excessive vertical vibration due to human-induced excitation (Pavic et al. 2007; Díaz et al. 2012; Nyawako et al. 2013). Hudson and Reynolds (2011; 2012; 2013) have developed active vibration control methods to attenuate excessive vibration caused by walking excitation on slender floors and achieved a number of satisfactory results with a number of in-service steel-concrete composite floor systems. This case study building will be used to investigate the potential of passive 
vibration control by the addition of non-structural vertical partitions and cladding to attenuate excessive floor vibrations due to walking excitation.

The non-structural partitions that were added to the case study building consist of lightweight plasterboard with a thickness of $12.5 \mathrm{~mm}$ and an approximate mass of $47 \mathrm{~kg} / \mathrm{m}$ (per metre length of the partition) supported on lightweight metal studs. These are identical type of partitions to those used in the real-life Charles Institute building (Devin 2013), which featured different structural frame, and are widely used in office buildings.

\section{FE Model of Case Study Building}

A detailed FE model, shown in Figure 2, of the case study building was created in ANSYS, using shell elements (Shell63) to model the slabs and shear cores. Beam elements (Beam4) were used to model the columns and beams. Due to the structural behaviour of the composite steel-concrete deck it was assumed that the floor had orthotropic properties. This was modelled using a lower Young's modulus for the concrete slab in the direction perpendicular to the spanning direction of the steel decking.

\subsection{Non-Structural Partitions \& Facades}

Each floor level is taken to be divided using lightweight non-structural partitions. There are a wide range of different partition and façade schemes available commercially. The various differences can include the degree of fixity at each end, the cross sectional detail and the eventual stiffness contributing (if at all) to dynamic properties.

For the purpose of considering the effect of partitions and facades on the structural response the systems used in the Charles Institute, a recently constructed building on the campus of 
University College Dublin, are assumed. The fairly standard framing system for these internal partitions is shown in Figure 3, while a schematic of the completed partition, which includes 'wallboards' and internal insulation is shown in Figure 4. Functionally the partitions are lightweight steel frames, fixed at top and bottom to the various floor slabs, to which 'wallboards' and internal insulation are fixed. Similarly, each external façade panel comprises a lightweight steel frame, fixed to floor levels at top and bottom, which in turn supports the polished basalt cladding panels which make up the building facade, Figure 5. At different stages of construction, with and without these non-structural elements, the Charles Institute floor was dynamically tested, using forced and free vibration test methods, to quantify the contribution of its partitions and facades to its dynamic properties. Numerical updating of finite element models was used to identify an appropriate strategy for modelling such partitions and cladding elements. For the vertical response of floor systems, linear elastic vertical springs, of appropriate stiffness, were found to be adequate. The resulting spring stiffness values identified for both internal partitions and external facades, which are used in this study, are listed in Table 1. This work is reported in detail in Devin and Fanning (2012) and Devin (2013).

In a manner consistent with these prior studies, the contribution of non-structural partitions and facades was modelled in the ANSYS FE model using a combination of vertical linear springs (Combin14) and lumped mass elements (Mass21), at 300mm centres, connected at both ends to the supporting floor and the floor above. This was done at each floor level, apart from the top floor which did not feature any partitions. The configuration of springs used in the FE model, for floor Level 1 is shown in Figure 6, and was replicated on all of the other four floors. This relatively simple modelling approach used to represent partitions, as simple vertical linear 
springs, is effective in modelling the contribution of non-structural elements to the vertical vibration response of individual floors.

\section{FE Model Modal Parameters}

Modal analysis was conducted on the bare frame FE model and the FE model including the partition springs, to examine the potential beneficial effects of consciously designing the partition layout to minimise floor vibrations due to walking excitation.

\subsection{Bare Frame FE Model}

Modal analysis was conducted in ANSYS to calculate the natural frequencies and mode shapes of Floor Level 1 which is the lowest floor in Figure 2. The floor had a first fundamental frequency of $5.27 \mathrm{~Hz}$, and the first three floor modes of Floor Level 1 are shown in Figure 7. The first natural frequency of this floor system, $5.27 \mathrm{~Hz}$, would be in the range considered as a 'low' frequency floor (Brownjohn \& Middleton 2008). Floors in this range are considered susceptible to developing resonances with walking excitation and are deemed to require careful analysis to avoid excessive floor vibration.

\subsection{FE Model with partitions}

Modal analysis was also conducted on the FE model with non-structural partitions added to attenuate floor vibrations due to walking excitation. The first three mode shapes of the FE model with partitions added are shown in Figure 8 . The first natural frequency of Floor Level 1 was 6.28 Hz. There is an obvious increase in natural frequencies from the bare frame to the bare frame with added non-structural partitions. This increase is attributed to the stiffening effect of the internal partitions. The first three natural frequencies have increased significantly by $19 \%$, 
$38 \%$ and $37 \%$, respectively. .As well as an increase in natural frequencies, the addition of internal partitions clearly affects the mode shapes calculated (Figure 7 and Figure 8).

\section{Walking Excitation Response}

To investigate the contribution and potential beneficial effects of the addition of non-structural partitions to a floor system, transient analysis was carried out subjecting the floor to walking excitation at four different locations. The vertical loading from a human walking was assumed to be cyclical, consisting of a combination of successive right and left footfalls (Fanning et al. 2005). Current vibration serviceability procedures (Smith et al. 2009) define the cyclical walking force using the following equation:

$F_{p}(t)=G+G \alpha_{1} \cos \left(2 \pi f_{p} t\right)+G \alpha_{2} \cos \left(4 \pi f_{p} t\right)+G \alpha_{3} \cos \left(6 \pi f_{p} t\right)+G \alpha_{4} \cos \left(8 \pi f_{p} t\right)$

Where $G$ is the force of the human walker (measured in Newtons), $f_{p}$ is the pacing frequency $(\mathrm{Hz}), t$ is time and $\alpha_{i}$ is denoted as the attenuation factor for each of the four harmonics specified as $0.5,0.2,0.1$ and 0.05 .

The vibration serviceability criterion recommended for offices is outlined by The Steel Construction Institute (Smith et al. 2009) and this method was followed to investigate the vibration serviceability of the case study building. The parameter to evaluate the vibration serviceability of floors in relation to human-induced excitation, is the 'Response Factor' (Smith et al. 2009) and is defined as the ratio between the weighted Root Mean Squared (RMS) acceleration and the threshold of human perception. The following formula is used to calculate the Response Factor of floors: 


$$
R=\frac{a_{w, r m s}}{0.005}
$$

Where $a_{w, r m s}$ is the weighted RMS acceleration response due to the walking excitation applied expressed in $\mathrm{m} / \mathrm{s}^{2}$. To confirm whether the two FE models used in this investigation satisfy this vibration criterion, as outlined above, four separate transient analyses were to be carried out on both models. The results of these analyses were presented by way of a Response Factor contour plot, whereby Response Factors were calculated at points located on the floor in a $3 \times 1.5 \mathrm{~m}$ grid (275 points in total). Interpolation was used to calculate the Response Factors between these points to form the contour plot of Response Factors for the entire floor. The floor was deemed to satisfy the vibration criterion if no point on the floor exceeded the target Response Factor of 4 for office buildings.

\subsection{Bare Frame Model}

The acceleration response of the bare frame FE model due to walking excitation applied (one at a time) at four different floor locations was calculated using transient analysis in ANSYS. The force applied for each of these four analyses was calculated using Eqn. (1). Pacing frequencies assumed varied between ...Hz and ...Hz, in steps of every ...Hz, i.e. pacing frequencies assumed were $1.4 \mathrm{~Hz}, 1.45 \mathrm{~Hz}, 1.1 \mathrm{~Hz}, \ldots, 1.95 \mathrm{~Hz}$ and $2.0 \mathrm{~Hz}$. An example of the acceleration response of the bare frame FE model due to walking excitation located at the mid-point of the bay located between gridlines 2-D and 3-C (Figure 1) is shown in Fig. 9. The maximum acceleration for the analysis was $0.0082 \mathrm{~g}$, which would be expected for floors of this type and would be considered to be in the range of forced excitation (Devin 2013).

The Response factors for a grid of locations across the floor of the bare frame FE model due to walking excitation in four locations are shown in Figure 10 - there are locations that exceed the 
response factor limit of 4 in all four load cases. Therefore in its current open-plan layout, this composite steel-concrete floor does not satisfy the vibration serviceability criterion. If this was found to be the case during the design stage of this building, alternative floor systems and/or alterations to the floor layout would have to be examined to solve the vibration serviceability issues or otherwise the floor could be susceptible to excessive floor vibrations, which would negatively affect the comfort of the building's occupants. For this case study building however, the possibility of improving the vibration response of the floor system by adding non-structural partitions in its FE model is examined.

\subsection{FE Model with partitions}

The acceleration response of the FE model with partitions added due to walking excitation, applied in a manner identical to the bare frame FE model (with the same pacing frequency range) at four different floor locations, was also calculated using transient analysis. An example of the acceleration response of the FE model with partitions added due to walking excitation located at the mid-point of the bay located between gridlines 2-D and 3-C is shown in Figure 11. The stiffness of the floor being investigated increased due to the addition of non-structural partitions as the maximum acceleration at this location with partitions is $0.007 \mathrm{~m} / \mathrm{s}^{2}$, compared to $0.0082 \mathrm{~m} / \mathrm{s}^{2}$, a reduction of $17 \%$.

The Response Factors for a grid of locations across the floor of the FE model, with partitions added, due to walking excitation in four locations are shown in Figure 12 and it is noted that there are no locations where the response factor limit of 4 is exceeded. For all four load cases and the maximum Response Factor is 3.2. Therefore the addition of non-structural partitions 
along gridlines $\mathrm{C}$ and $\mathrm{D}$ (Figure 1) reduce the floor vibrations adequately so that no area of the floor exceeds the Response Factor limit of 4 for office floors.

\section{Vibration Transmission Investitation}

A vibration transmission transient analysis was conducted on the FE model, with partitions added, which investigated the level of vibration transmission between Floor Levels 1 and 2 (Figure 2). A sweeping 'chirp' force was applied to Floor Level 1 at the midspan of the internal partition located along gridline $\mathrm{C}$, between gridlines 2 and 3 (Figure 1). The frequency range for the tests was $5 \mathrm{~Hz}$ to $40 \mathrm{~Hz}$, sweeping a rate of $0.63 \mathrm{~Hz}$ per second. The resulting vibration response of Floor Levels 1 and 2 at the midspan of the partition is shown in Figure 13. The acceleration time histories at three locations on each floor were used to calculate the percentage vibration transmissibility (percentage of vibration from Floor Level 1 present on Floor Level 2) and the percentage of vibration transmission between floors is plotted against time in Fig. 14. Table 2 summarises the average and maximum transmission values which occurred during the test. The FE model featuring partitions transmitted an average $21.7 \%$ of the vibration on Floor Level 1 to Floor Level 2, with maximum transmission being over $75 \%$.

Therefore, this non-structural vibration transmission could have implications on floor vibration serviceability due to the fact that walking excitation on a floor below and/or above the floor being checked for vibration serviceability may have higher levels of excitation than expected due to the fact that vibrations may be transmitted through the connecting structural and non-structural elements. This feature of non-structural elements is currently not accounted for in floor vibration design guidelines and could unexpectedly and significantly increase the acceleration a floor is subject to. In addition to this, these results would indicate that modelling a single floor of a 
building may not always be appropriate and a model of the entire structural system may be required to account accurately for vibration transmission between floors or at least increase the estimated floor vibrations experienced by a certain factor to account for this transmission.

\section{Discussion of Results}

The focus of this study was to investigate the potential of non-structural partitions to reduce excessive floor vibrations due to human-induced vibrations on slender floors. Additionally the procedures recommended by the Steel Construction Institute in the 'Design of Floors for Vibration: A New Approach' (SCI P354) (Smith et al. 2009) is examined.

Having demonstrated previously in (Devin et al. 2012; Devin 2013), that non-structural elements can have a substantial impact on the dynamic response of floor systems, a case study building, consisting of a steel-concrete composite floor system, was developed according to Eurocode 4 (STN 1994) and an FE model of the building was created in ANSYS. Modal analysis of the FE model calculated the first natural frequency of Floor Level 1 as $5.27 \mathrm{~Hz}$, above the recommended limit value of $4 \mathrm{~Hz}$ but still within the range susceptible to resonance due to walking excitation (typically in the $1.5 \mathrm{~Hz}$ to $10 \mathrm{~Hz}$ range). Therefore a floor with such dynamic properties would require careful design consideration to avoid unwanted vibrations due to human-induced loading. On applying walking excitation at a range of pacing frequencies at four locations of the FE model using transient analysis, this floor did not satisfy the vibration limit set out in SCI P354 (Smith et al. 2009).

The next step was to evaluate the potential of adding non-structural partitions to the building to lessen the floor vibrations so that it would satisfy the vibration serviceability criterion. The non- 
structural partitions were modelled in the FE model using vertical linear spring-mass elements (Combin14 and Mass21 elements) which had been previously developed in (Devin 2013). With the addition of partitions, the first natural frequency of Floor Level 1 increased from $5.27 \mathrm{~Hz}$ to $6.28 \mathrm{~Hz}$ (an increase of 19\%). On examining the floor response due to walking excitation, an average reduction of $17 \%$ in peak accelerations occurred due to the addition of the non-structural partitions. The entire floor now had response factors less than the recommended limit of 4 for office buildings. The average percentage reduction of Response factors from the bare frame to bare frame with partitions included was $42 \%$. Table 3 compares the maximum response factors for all analyses conducted on the bare frame FE model and bare frame FE model with partitions added.

In addition to the investigation of floor vibration serviceability of the case study building, transient analysis examining the vibration transmission capability of the combined system consisting the structural frame and non-structural vertical full-height partitions was also carried out. The results of this numerical analysis are compared to similar experimental vibration transmission tests conducted on Floor Levels 1 and 2 of the Charles Institute floor featuring the same partition type but different structural frame. The same sweeping 'chirp' excitation force was applied vertically using an electrodynamic shaker adjacent to the non-structural partitions and cladding panels of this structure. Three sensors adjacent to the non-structural elements on Floor Levels 1 and 2 were used to measure the floor vibration on each floor level. Acceleration time histories at the midspan of the cladding panels and internal partitions are shown in Figure 15 and Figure 16, respectively.

Similar to the FE simulations presented previously in this paper, the measured acceleration time histories recorded from each of these sensors were used to calculate the percentage vibration 
transmissibility (percentage of vibration from Floor Level 1 present on Floor Level 2) of both the cladding panels and internal partitions. The resulting percentage transient levels for the cladding panels and internal partitions are plotted versus time in Fig. 17 and 18, respectively. The internal partitions transmitted an average of $32 \%$ of the floor vibrations on Floor Level 1 up to Floor Level 2, whilst the cladding panels only transmitted $18 \%$. Vibration transmission levels of both non-structural elements are summarised in Table 4. The maximum vibration transmission measured was $46 \%$ and $65 \%$, for the cladding and partition tests, respectively. This implies that, non-structural partitions, due to their more direct connection to floor systems have a higher potential to transmit vibration between floors. In contrast, the cladding panels of this specific structure were not directly attached to the floors, but were connected to a separate supporting system, and therefore their capacity to transmit vibrations to the floor system above was lower than the partitions connected directly to the floor.

Comparing the response of the numerical vibration transmission test, which was conducted on the case study building, to the experimental tests carried out on the Charles Institute, it is obvious that the perecntage of maximum transmitted vibrations was similar: $75.8 \%$ of the vibration on Floor Level 1 to Floor Level 2 in the FE model, compared to a maximum of $65 \%$ for the partition located in the Charles Institute.

In the case study presented in this paper, a partition layout is recommended which solves the vibration serviceability issues of the floor system. It should be noted, like with many structural design issues, that this is only one of many possible solutions. In this case, there are many other possible non-structural partition layouts which potentially could be a more efficient solution. However, a parametric investigation of the most efficient non-structural partition layouts in 
terms of structural efficiency, functionality and cost-effectiveness is beyond the scope of this study.

This paper studies the effects of non-structural elements to mitigate excessive vibrations of steelconcrete composite floor systems. The test building used for the vibration testing of the nonstructural partitions and cladding components, the Charles Institute building, had relatively stiff floors due to the low vibration threshold required for the state-of-the-art medical laboratories it housed. However, as was shown in the case study carried out on the steel concrete composite building, it is evident that non-structural elements may have an even more significant effect on these structures due to their higher slenderness value and lower potential energy dissipation capability. It is also shown from both the experimental and numerical results presented that numerical models that neglect the effect of non-structural elements will underestimate the stiffness of the structure and result in vibration serviceability assessments that will be overly conservative, thereby comprising the uptake of these newer, and more structurally efficient design solutions. In addition, building owners and designers should recognise that movement of internal partitions to facilitate changes in usage requirements may indeed affect the vibration response perceived by occupants. Finally, the results highlighted by this study indicate that in structures where vibration serviceability is a critical issue, there is potential to alleviate this by judicious placement of internal partitions above and/or below the floor level of concern.

\section{Conclusions}

A case study building of a slender steel-concrete composite floor system highlighted the potential benefits of judicious placement of internal partitions above and/or below a floor to reduce excessive floor vibration to acceptable levels. In addition, numerical and experimental 
vibration transmission simulations were conducted on the case study model and compared with the full-scale test results form the real-life floors in the Charles Institute building faturing same type of partitoions but different structural frame.

Conclusions drawn from this case study and comparison of the numerical and experimental vibration transmission tests are as follows:

- There was a significant increase of $19 \%$ between the first natural frequency of the FE models of the bare frame and of the are frame with non-structural partitions added.

- The inclusion of partitions also reduced the peak acceleration response of the floor by an average of $17 \%$ for each walking excitation location. Therefore it is argued that non-structural partitions have the potential to enhance vibration serviceability of floors.

- In addition to acceleration response, the inclusion of internal partitions to the FE model reduced the overall Response Factors of the floor. The maximum Response Factor of 7.4 was reduced to 3.2 when non-structural partitions were taken into account. Therefore, the case study floor was transformed from a floor with unsatisfactory vibration serviceability to a floor which satisfied the vibration serviceability limits (a maximum response factor of 4) set for office buildings.

- Numerical and experimental investigation of the vibration transmission between floors featuring non-structural elements quantified the amount of transmission which can be as high as $60 \%$.

- Significant vibration transmission potentially has implications on floor vibration serviceability due to vibrations transmitted from a floor below or above which could increase the vibrations experienced on the floor analysed above the levels estimated if transmission is neglected.

- The vibration transmission tests on a real-life building also highlighted that different nonstructural vertical partition and cladding elements have different vibration transmission 
behaviour. The non-structural partition tested on the Charles Institute transmitted on average $32 \%$ of the vibration experienced on Floor Level 1 to Floor Level 2. In contrast the cladding panel tested transmitted an average of only $18 \%$. This difference in the levels of transmission was attributed to the different material properties and connection details of the non-structural elements in question.

- It is important to recognise that non-structural vibration transmission has implications on the methods used to predict floor vibrations at the design stage; as it may be required to model all floors of the structure to account for vibration transmission or increase the accelerations experienced on a given floor by a factor relating to the non-structural vibration transmission.

Finally, it is the authors' opinion that these findings present interesting opportunities to both designers and partition suppliers. With the evidence presented in this study, the tools required for designers to integrate the non-structural components in their design are a step closer. In addition, there is potential for partition suppliers to specify bespoke partition systems that are designed to avoid or enhance, coupling between the partition systems and the floor response, to the benefit of increasing the structural efficiency of a floor system.

\section{Acknowledgments}

The authors wish to express their gratitude to: (i) the Irish Research Council for Science, Engineering \& Technology (IRCSET) grant no. RS2000810, (ii) the UK Engineering and Physical Sciences Research Council EPSRC grant ref. EP/G061130/2, (iii) Dr Christopher Middleton for his help with the technology used in this work and in particular the field testing at UCD and (iv) the UCD Buildings Office for access to the Charles Institute. 


\section{References}

Alkhatib, R. \& Golnaraghi, M., 2003. Active structural vibration control: a review. Shock and Vibration Digest, September.

Brownjohn, J.M.W. \& Middleton, C.J., 2008. Procedures for vibration serviceability assessment of high-frequency floors. Engineering Structures, 30(6), pp.1548-1559.

Brownjohn, J.M.W. \& Pavic, A., 2006. Vibration control of ultra-sensitive facilities. Proceedings of the ICE - Structures and Buildings, 159(5), pp.295-306.

Chen, S. et al., 2012. Semi-Active Tuned Mass Damper for Vibration Control in High-Tech Fab. In 2nd International Conference on Mechanical, Production and Automobile Engineering (ICMPAW 2012). Singapore.

Choi, K. \& Cho, S., 2004. Semi-active fuzzy control for seismic response reduction using magnetorheological dampers. Earthquake engineering \& Structural Dynamics, 33(723736).

Crosby, M., Harwood, R. \& Karnopp, D., 1974. Vibration control using semi-active force generators. ASME Journal of Engineering Industry, 26, pp.619-626.

Datta, T., 2003. A state-of-the-art review on active control of structures. ISET Journal of earthquake technology, 40(1), pp.1-17.

Devin, A. \& Fanning, P.J., 2012. The Evolving Dynamic Response of a Four Storey Reinforced Concrete Structure during Construction. Shock and Vibration, 19(5), pp.1051-1059.

Devin, A., 2013. The Effect of Non-structural elements on the Vertical Dynamic Response of Floors. PhD Thesis. School of Civil, Structural and Environmental Engineering, University College Dublin.

Díaz, I. et al., 2012. Enhancing active vibration control of pedestrian structures using inertial actuators with local feedback control. Engineering Structures, 41, pp.157-166.

Dyke, S. \& Spencer, B., 1996. Modeling and control of magnetorheological dampers for seismic response reduction. Smart materials and structures, 5(5). Available at: http://iopscience.iop.org/0964-1726/5/5/006 [Accessed July 12, 2013].

Fanning, P., Archbold, P. \& Pavic, A., 2005. A Novel Interactive Pedestrian Load Model for Flexible Footbridges. In Proceeding of the 2005 Society for Experimental Mechanics Annual Conference on Experimental and Applied Mechanics. Portland, Oregan, pp. 7-9. 
Hudson, M. \& Reynolds, P., 2013. Potential benefi ts of incorporating active vibration control in floor structures. The Structural Engineer, (Feburary), pp.46-48.

Hudson, M., Reynolds, P. \& Nyawako, D., 2011. Efficient design of floor structures using active vibration control. In Structures Congress 2011.

Hudson, M.J. \& Reynolds, P., 2012. Implementation considerations for active vibration control in the design of floor structures. Engineering Structures, 44, pp.334-358.

Li, Q.S. et al., 2002. Field measurements of amplitude-dependent damping in a 79-storey tall building and its effects on the structural dynamic responses. The structural design of tall buildings, 11(2), pp.129-153.

Miskovic, Z., Pavic, A. \& Reynolds, P., 2009. Effects of full-height nonstructural partitions on modal properties of two nominally identical building floors. Canadian Journal of Civil Engineering, 36(7), pp.1121-1132.

Nyawako, D., Reynolds, P. \& Hudson, M., 2013. Findings with AVC design for mitigation of human induced vibrations in office floors. In Topics of Dynamics in Civil Structures, Volume 4. Springer, New York, pp. 37-44.

Pan, T.-C., You, X. \& Brownjohn, J.M.W., 2006. Effects of infill walls and floor diaphragms on the dynamic characteristics of a narrow-rectangle building. Earthquake Engineering \& Structural Dynamics, 35(5), pp.637-651.

Pavic, A. et al., 2001. Critical review of guidelines for checking vibration serviceability of posttensioned concrete floors. Cement and Concrete Composites, 23(1), pp.21-31.

Pavic, A., Miskovic, Z. \& Reynolds, P., 2007. Modal Testing and Finite Element model updating of a lively open-plan composite building floor. Journal of Structural Engineering, 133(4), pp.550-558.

Pavic, A., Widjaja, T. \& Reynolds, P., 2002. The use of modal testing and FE model updating to investigate vibration transmission between two nominally identical building floors. In Proc., Int. Conf. on Structural Dynamics Modeling-Test, Analysis, Correlation and Validation. Instituto Superior Tecnico Lisbon, Portugal, pp. 347-355.

Ren, W. \& Chen, H., 2010. Finite element model updating in structural dynamics by using the response surface method. Engineering Structures, 32(8), pp.2455-2465.

Reynolds, P., 2000. The effects of raised access flooring on the vibrational performance of longspan concrete floors. PhD Thesis: University of Sheffield.

Saidi, I. et al., 2011. Development of passive viscoelastic damper to attenuate excessive floor vibrations. Engineering structures, 33(12), pp.3317-3328. 
Smith, A., Hicks, S. \& Devine, P., 2009. Design of Floors for Vibration: A New Approach 2nd Ed. Re., Assot, Berkshire.

Soong, T. \& Costantinou, M., 1994. Passive and active structural vibration control in civil engineering, New York: Spring-Verlag.

STN, E., 1994. 1-1: Eurocode 4: Design of composite steel and concrete structures,

Symans, M. \& Constantinou, M., 1999. Semi-active control systems for seismic protection of structures: a state-of-the-art review. Engineering structures, 21(6), pp.469-487.

Ventura, C.E., Lord, J.-F. \& Simpson, R.D., 2002. Effective use of ambient vibration measurements for modal updating of a 48 storey building in Vancouver, Canada. In International Conference on Structural Dynamics Modeling - Test, Analysis, Correlation and Validation. Madeira Island, Portugal.

Yang, J. \& Soong, T., 1988. Recent advances in active control of civil engineering structures. Probabilistic Engineering Mechanics, 3(4), pp.179-188. 
Table 1: Stiffness value of non-structural partitions used in the case study FE model.

\begin{tabular}{|l|l|}
\hline Stiffness Per Spring (kN/m) & 11000 \\
\hline Stiffness per unit width (kN/m)/m & 36630 \\
\hline
\end{tabular}

Table 2: Summary of average and maximum percentage floor vibration transmission values between Floor Levels 1 and 2 of the numerical model of the case building.

\begin{tabular}{|l|l|}
\hline Average & $21.7 \%$ \\
\hline Maximum & $75.8 \%$ \\
\hline
\end{tabular}

Table 3: Comparison of maximum response factors for each test conducted on both the bare frame FE model and FE model with non-structural partitions added.

\begin{tabular}{cccc}
\hline $\begin{array}{c}\text { Walking } \\
\text { Test }\end{array}$ & $\begin{array}{c}\text { BE } \text { model } \\
\text { w/ partitions }\end{array}$ & $\begin{array}{c}\text { FE model } \\
\text { (\%) }\end{array}$ \\
\hline 2 & 7.4 & 3.2 & $-56 \%$ \\
3 & 4.4 & 3.2 & $-27 \%$ \\
4 & 6.9 & 3.2 & $-54 \%$ \\
\hline
\end{tabular}


Table 4: Comparison of measured vibration transmission on the Charles institute floor.

\begin{tabular}{ccc} 
Non-structural Element & Average & Maximum \\
\hline Cladding & $18 \%$ & $46 \%$ \\
Partitions & $32 \%$ & $65 \%$ \\
\hline
\end{tabular}




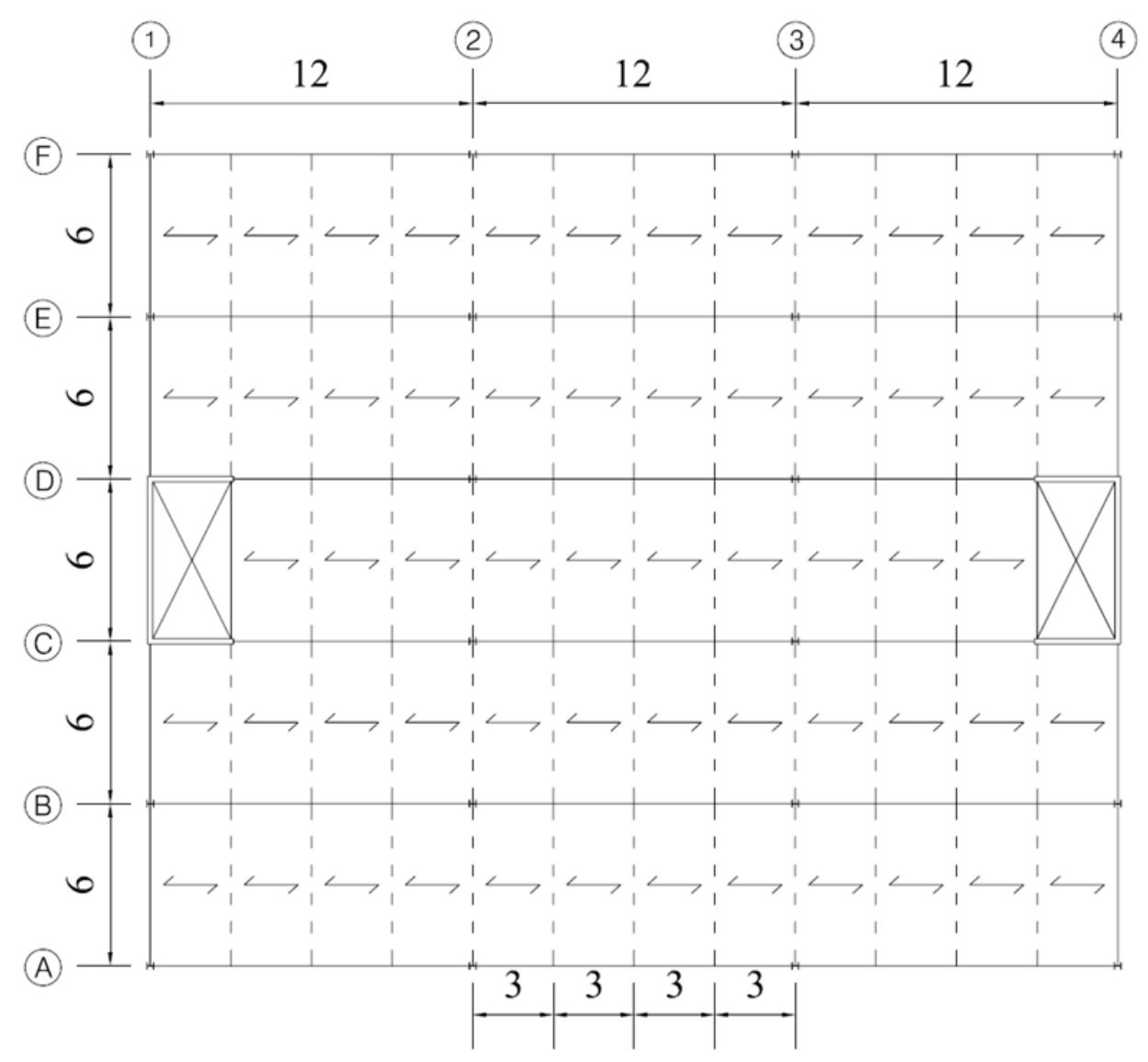

Figure 1: Typical floor layout of case study building.

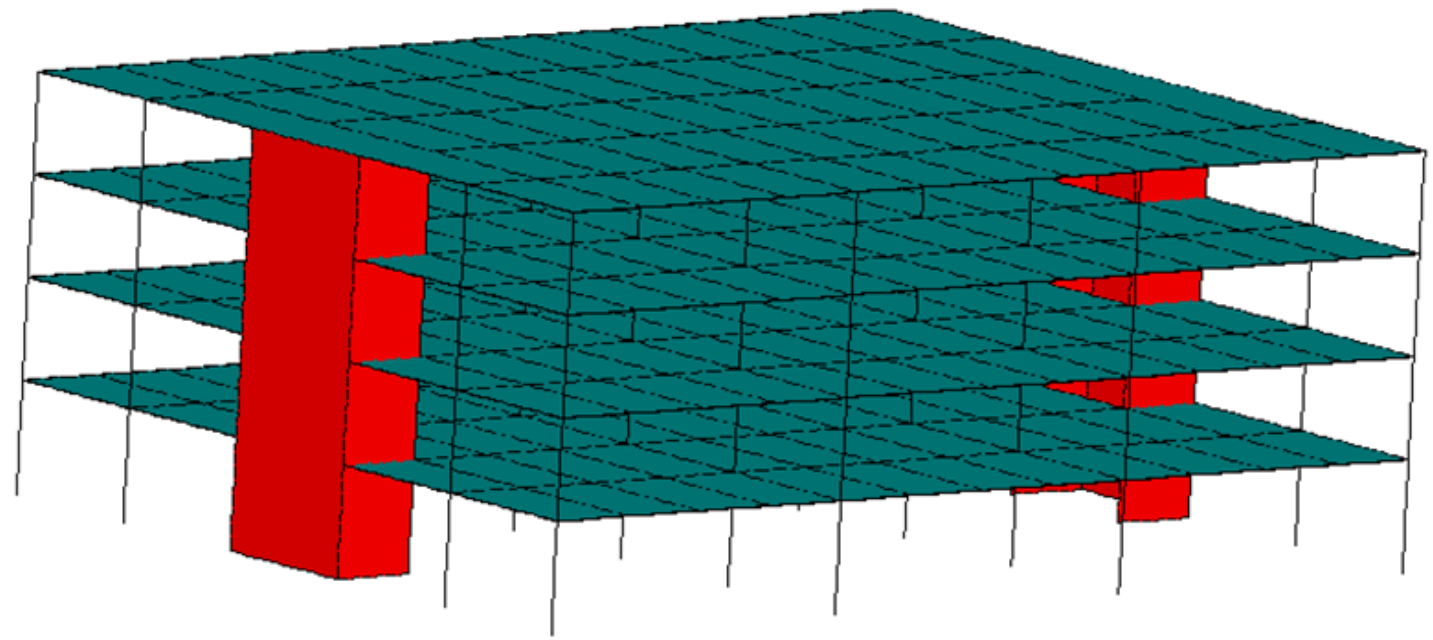


Figure 2: FE Model of Case Study Building..

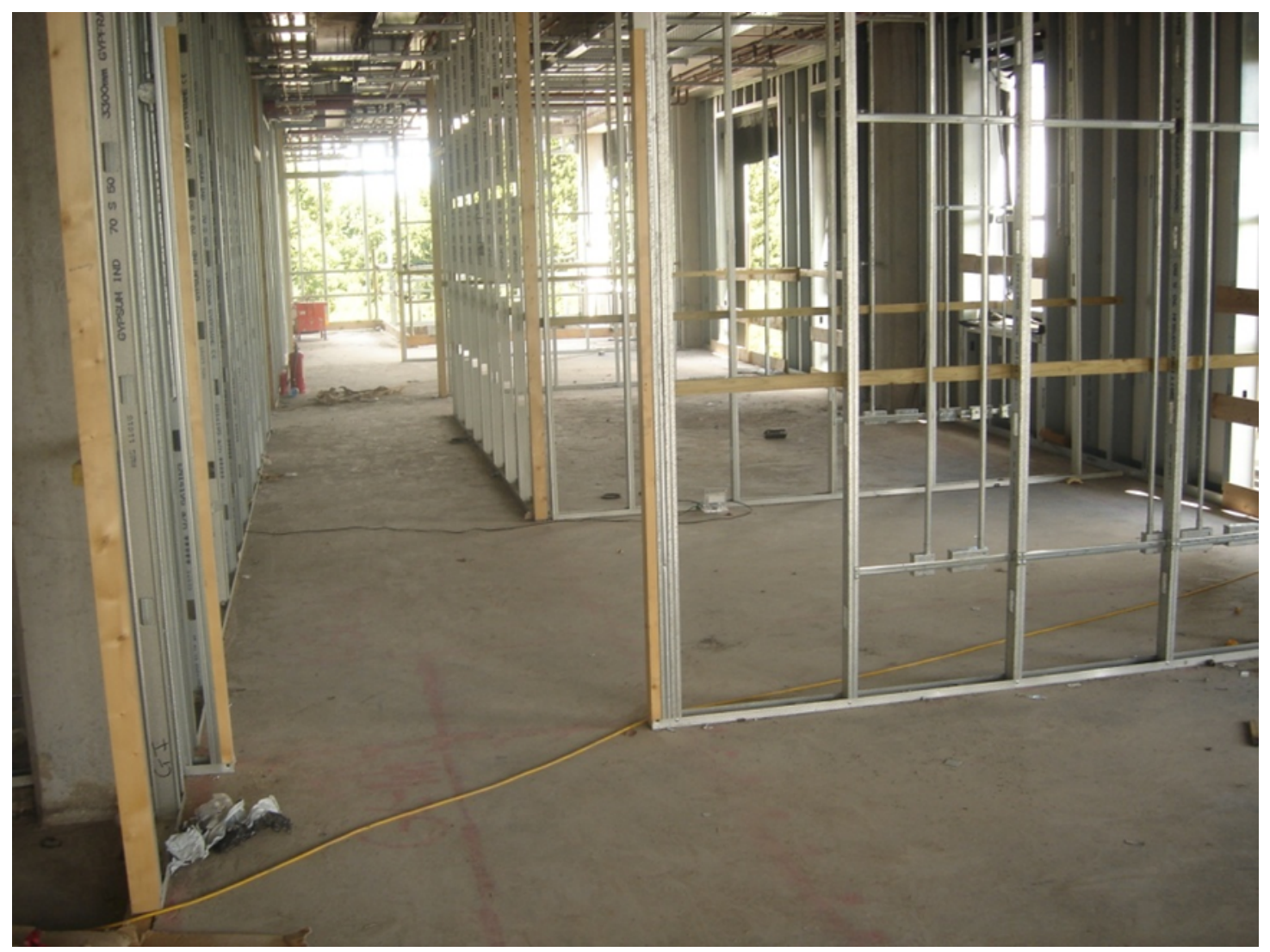

Figure 3: Framing system for internal partitions (Photos: A. Devin) 


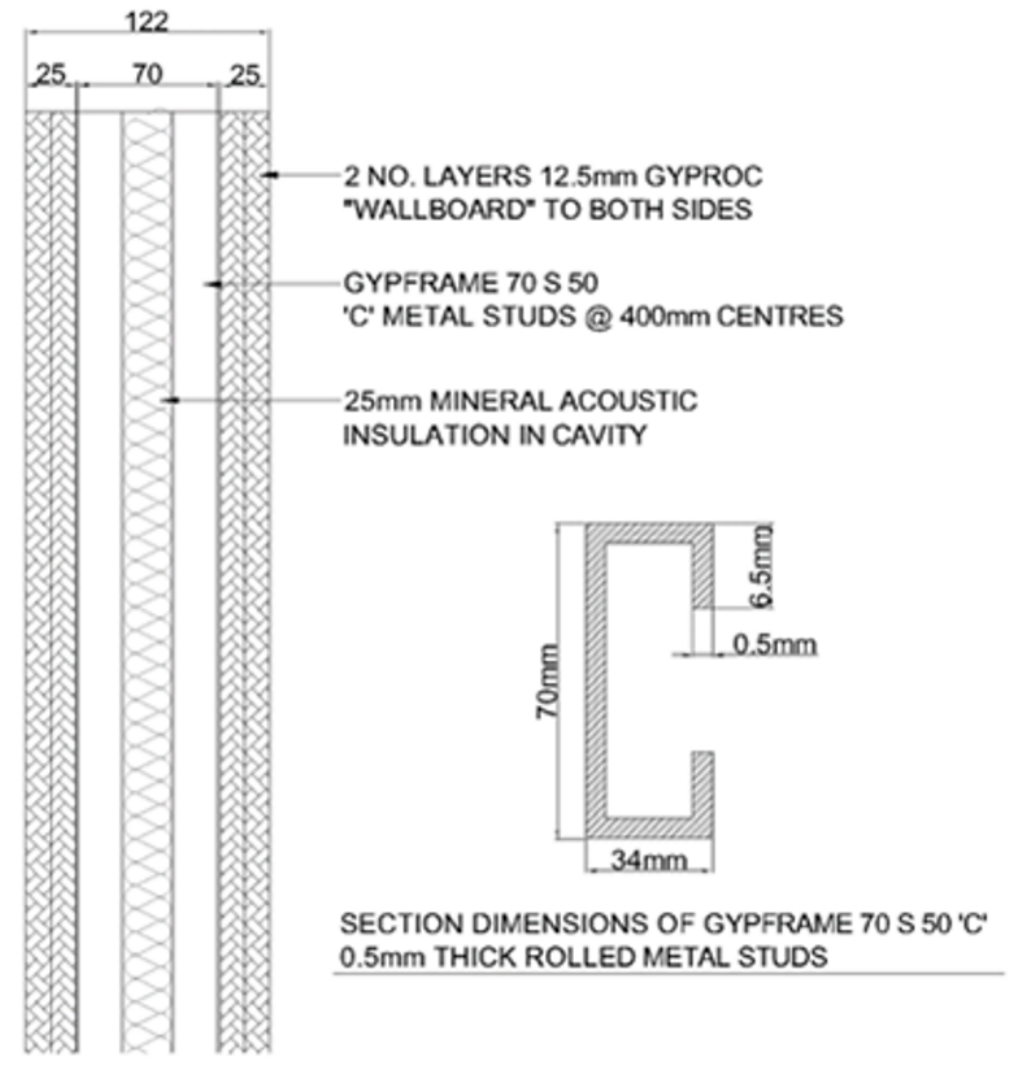

Figure 4: Detail of Partition Element. 


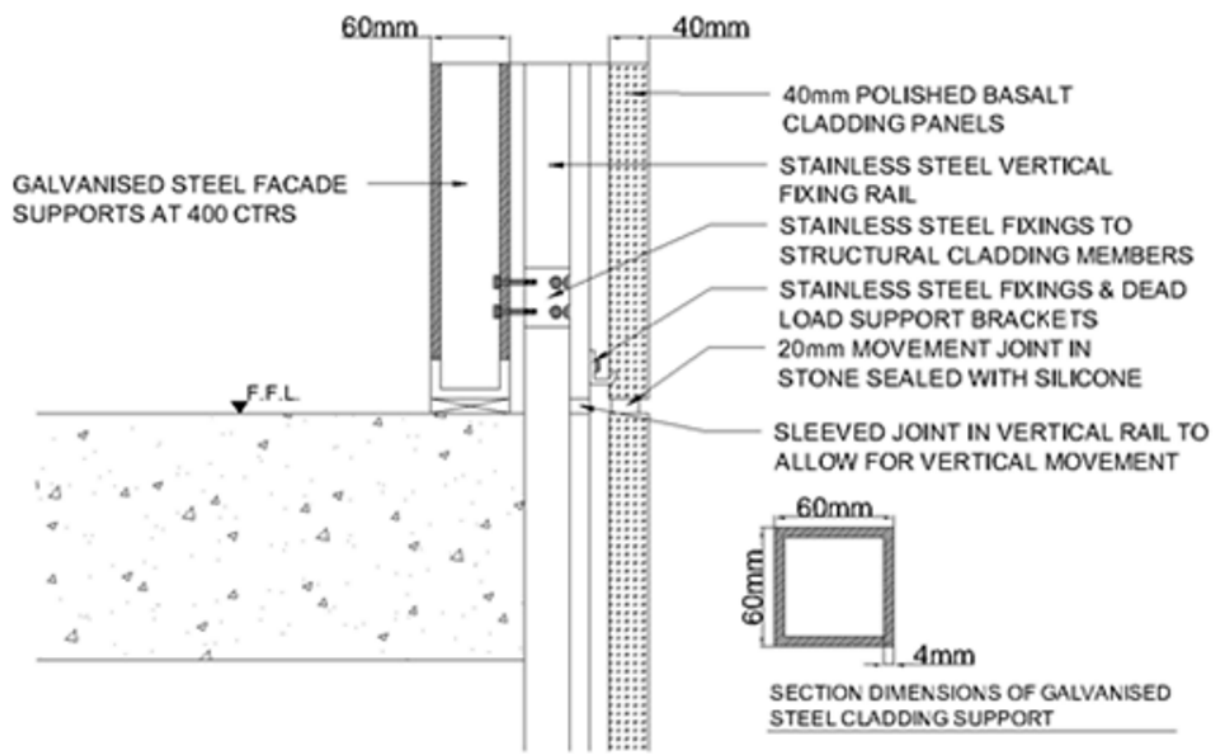

Figure 5: Detail of cladding connection to structure.

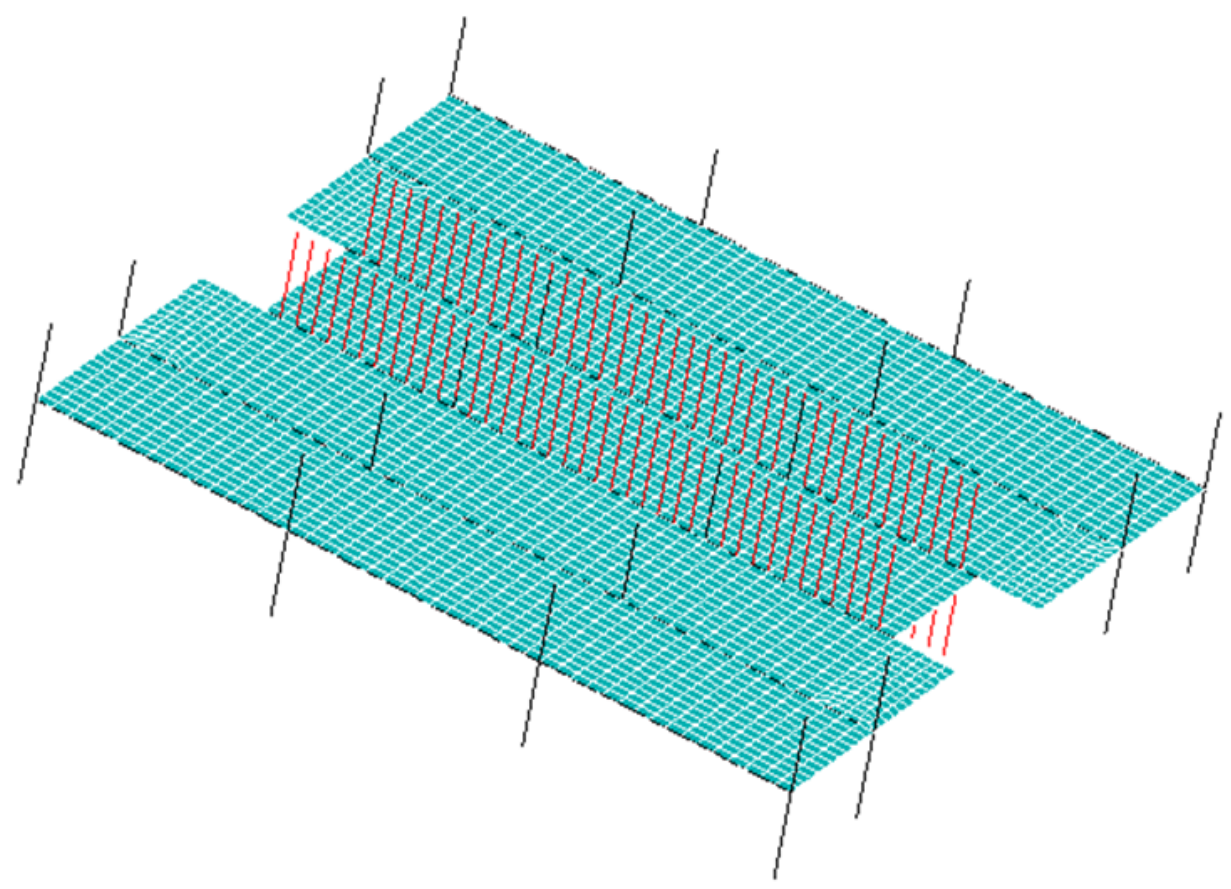

Figure 6: Representation of partitions in numerical model. 


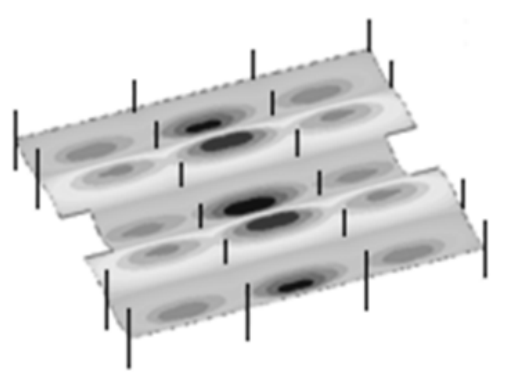

$5.27 \mathrm{~Hz}$

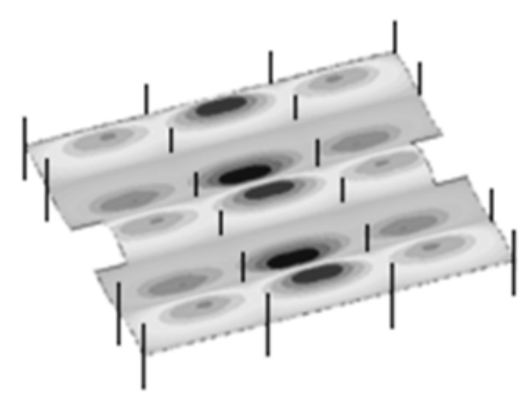

$5.55 \mathrm{~Hz}$

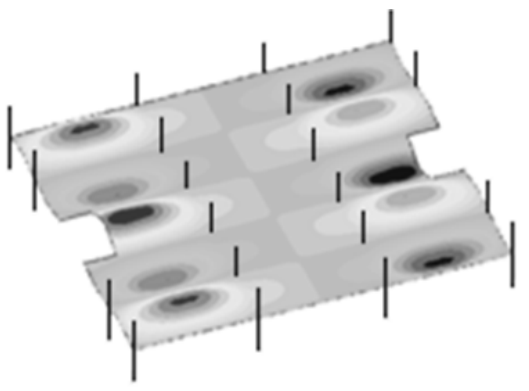

$5.67 \mathrm{~Hz}$

Figure 7: First three floor Level 1 mode shapes of the bare frame FE model.
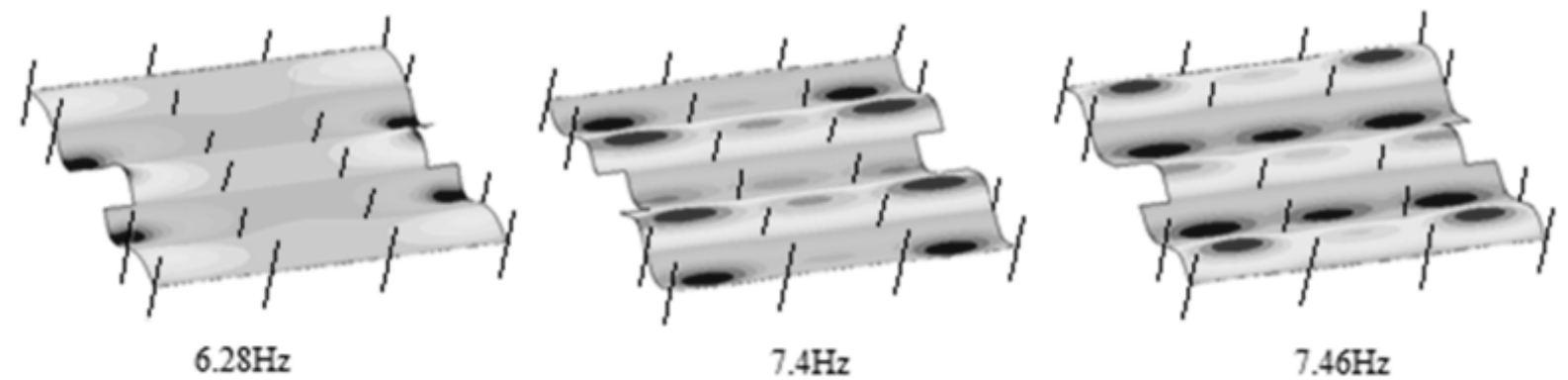

Figure 8: First three floor mode shapes of the FE model with non-structural partitions added.

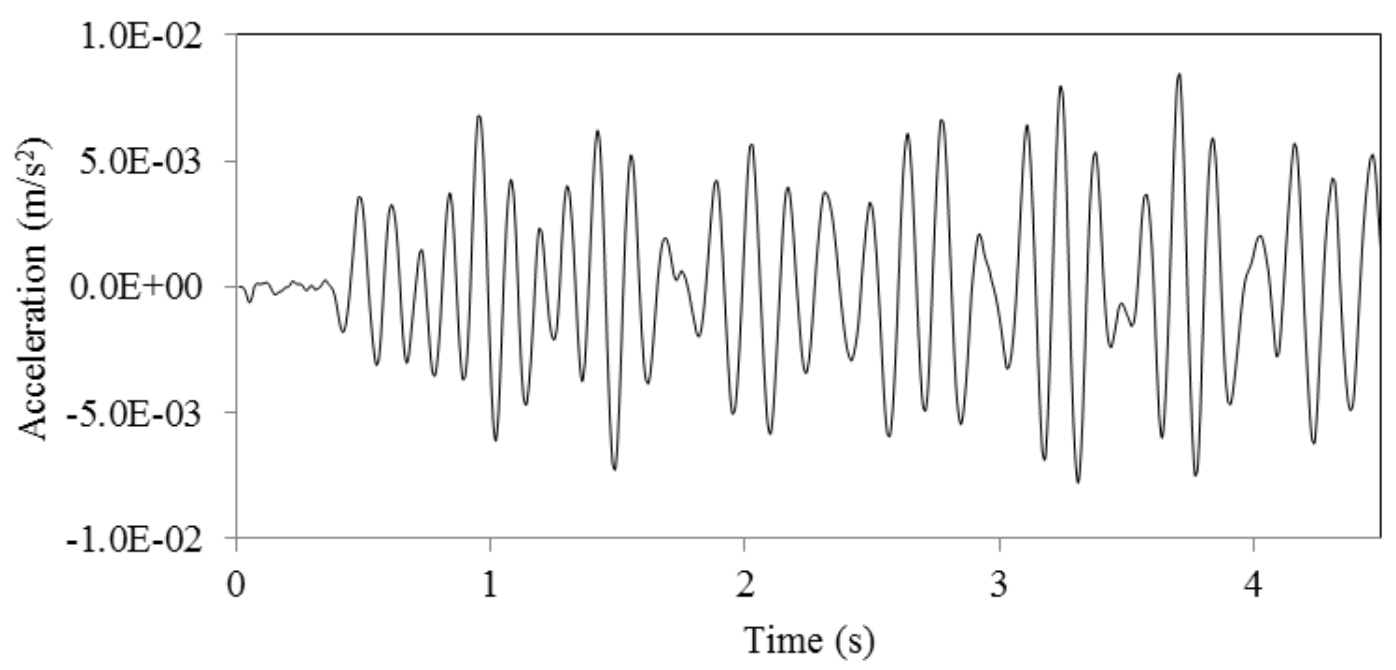


Figure 9: Sample acceleration time history of walking-induced floor vibration extracted from the bare frame FE model.
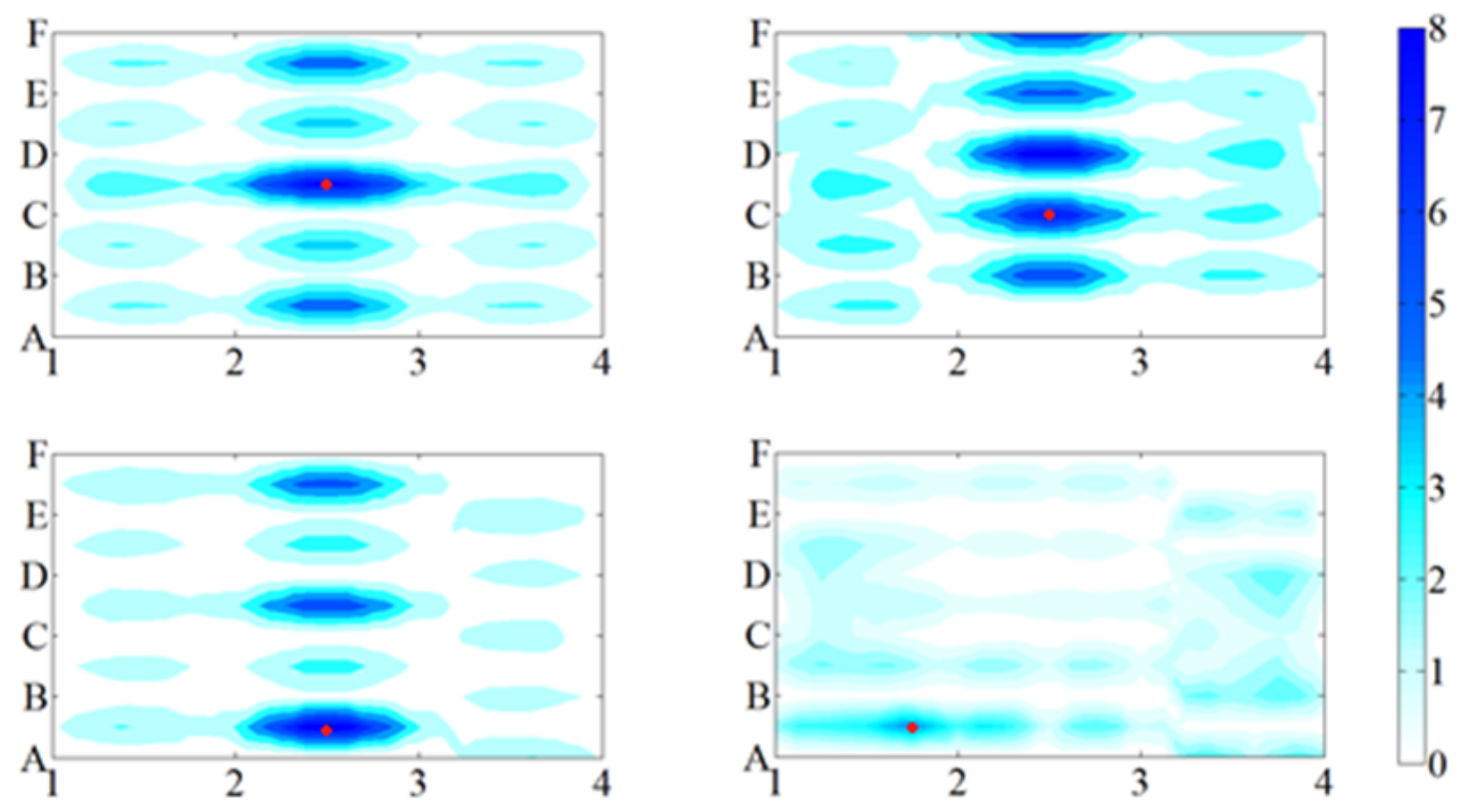

Figure 10: Response factors shown as gradient calculated due to walking excitation at four different locations (marked with a black dot) on the bare frame FE model, with a maximum response factor of 8 . 


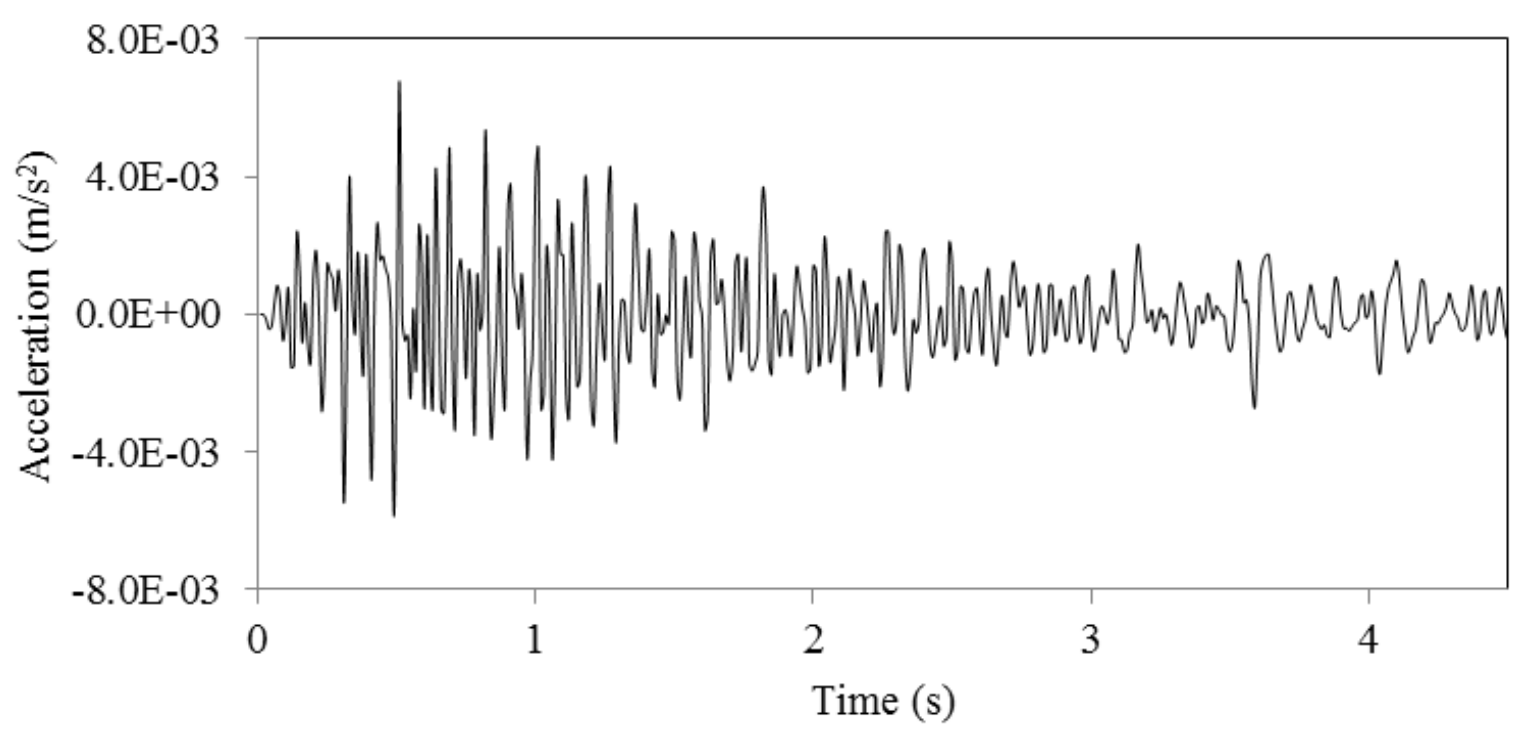

Figure 11: Sample acceleration time history of walking-induced floor vibration.
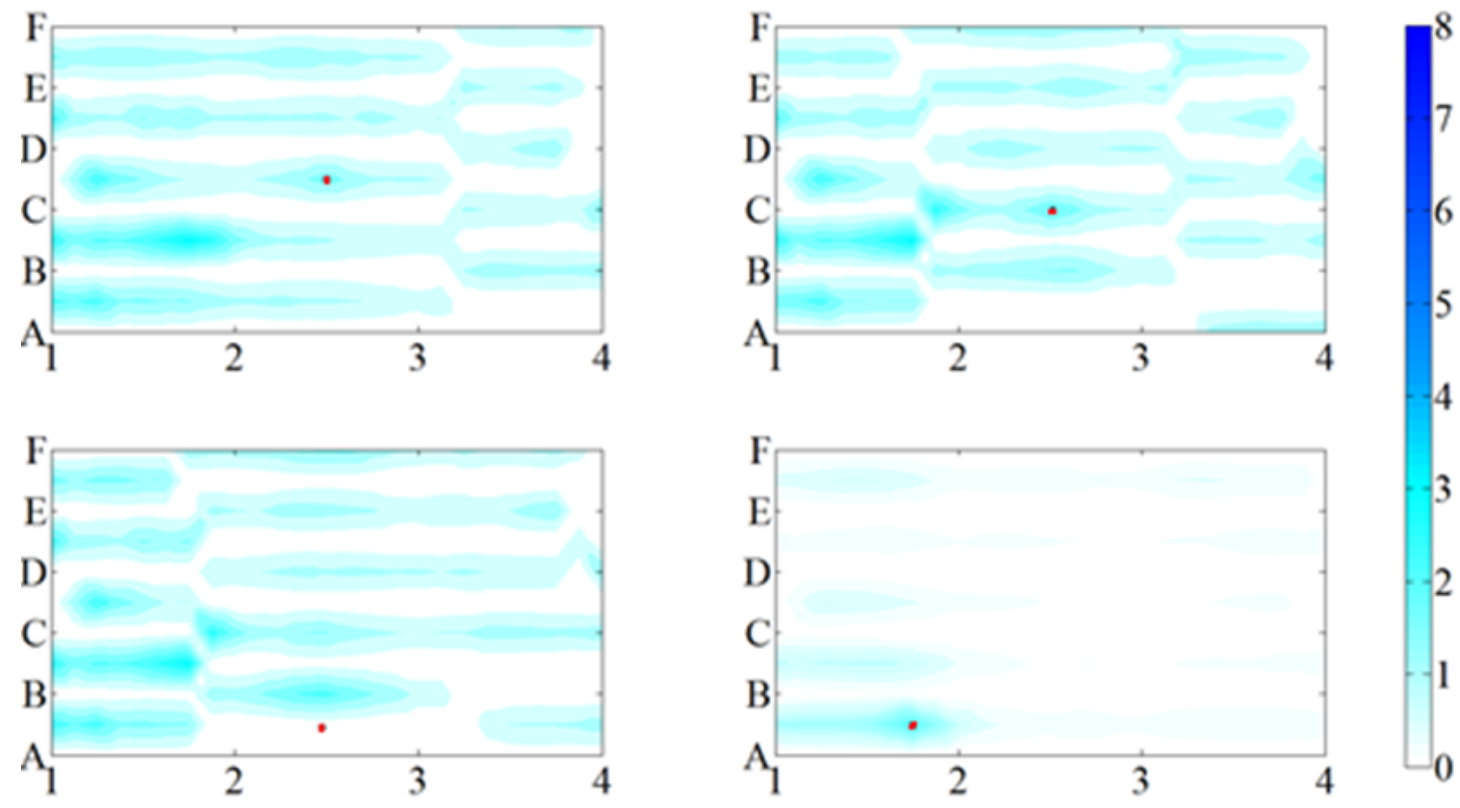

Figure 12: Gradient plot of response factors calculated due to walking excitation at four different floor locations (marked with a black dot) on the FE model with non-structural partitions added, with a maximum response factor of 3.2 . 


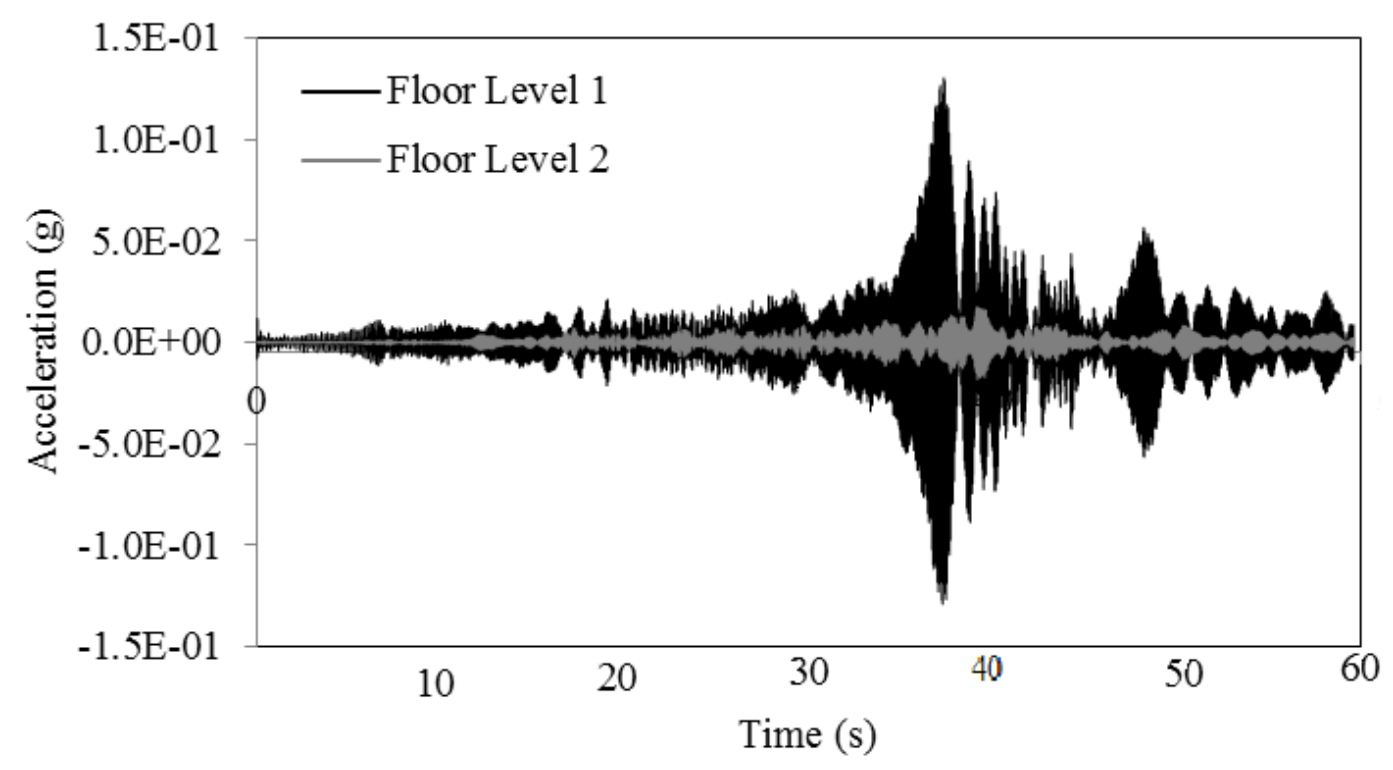

Figure 13: Acceleration time history at the midspan of the internal partition located between gridlines C-2 and C-3 on Floor Levels 1 and 2 of the numerical model of the case study building.

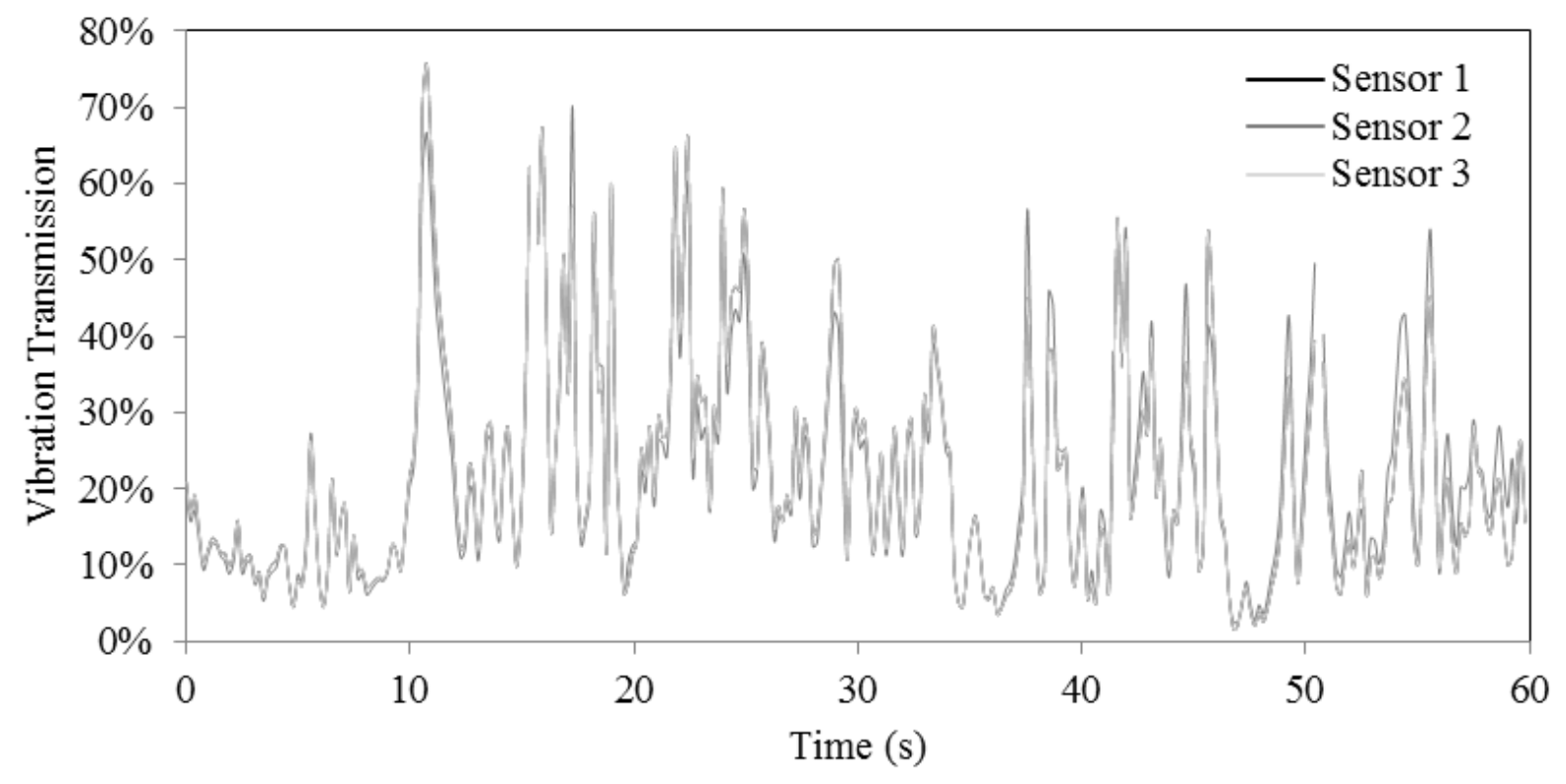


Figure 14: Percentage of vibration transmission between Floor Levels 1 and 2 along the internal partition located between gridlines $\mathrm{C}-2$ and $\mathrm{C}-3$ of the case study building.

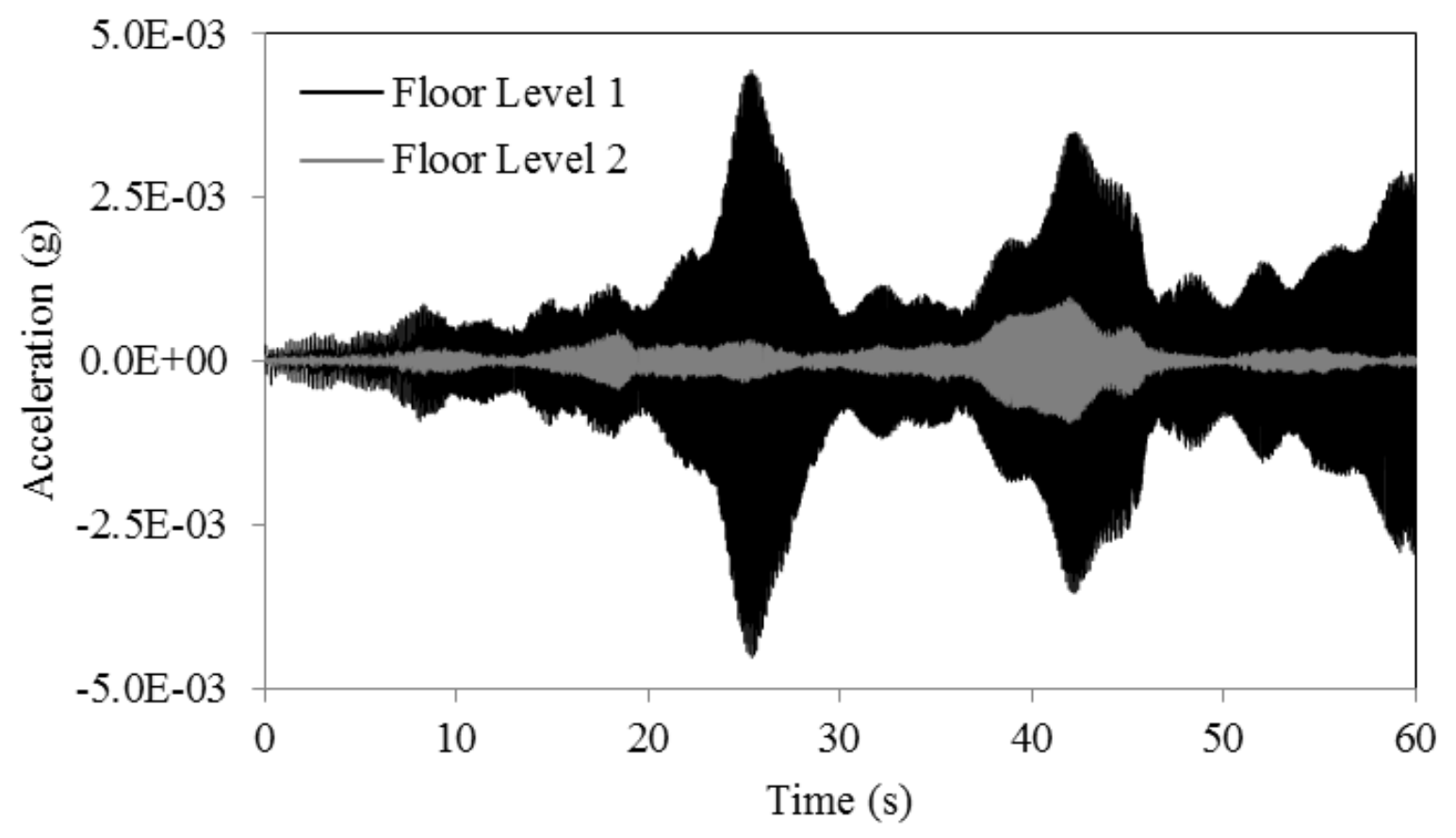

Figure 15: Acceleration time histories recorded at the midspan of the cladding panel during the cladding vibration transmission test from the Charles Institute research facility. 


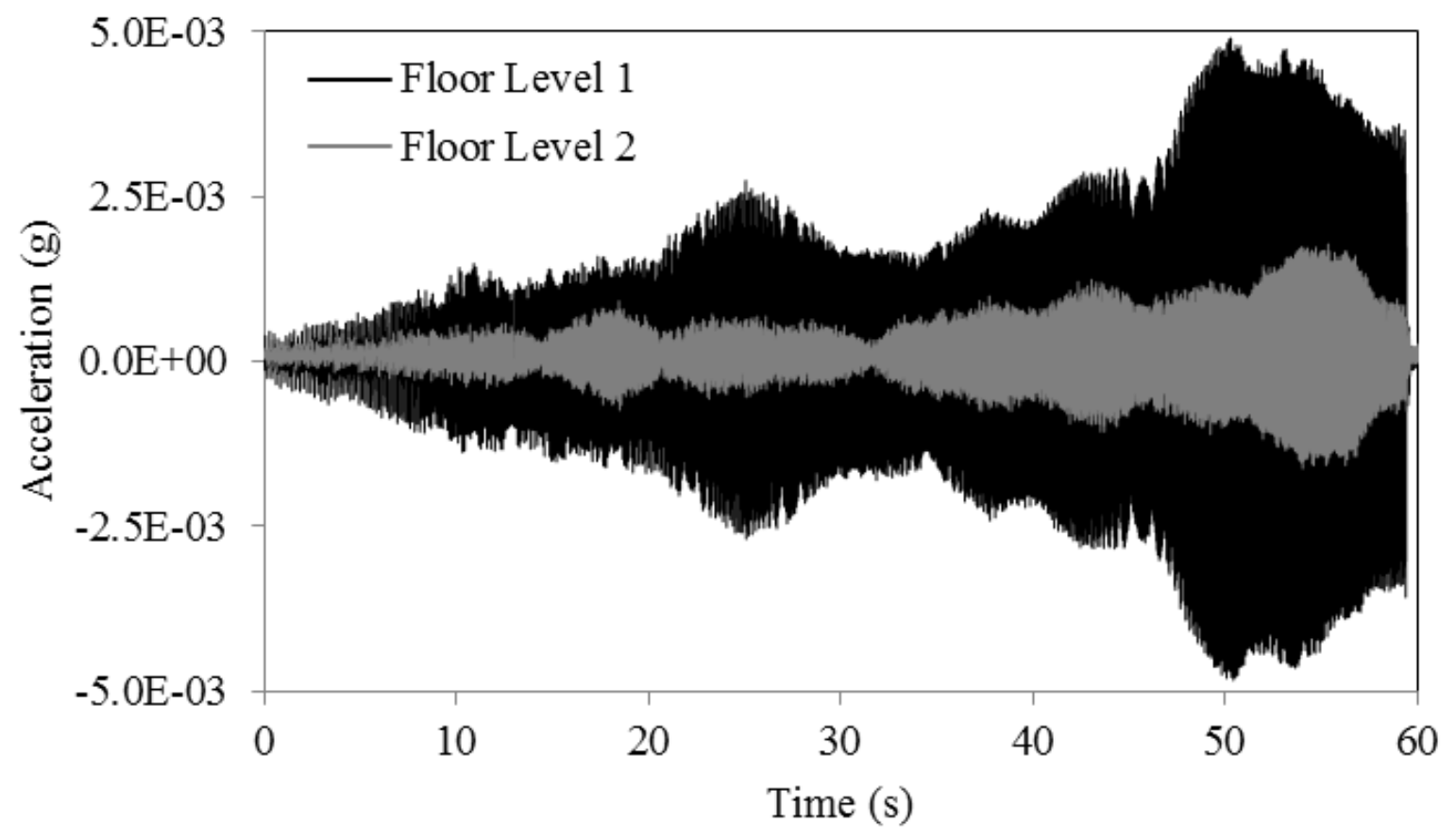

Figure 16: Acceleration time histories recorded at the midspan of the internal partition during the partition vibration transmission test from the Charles Institute research facility.

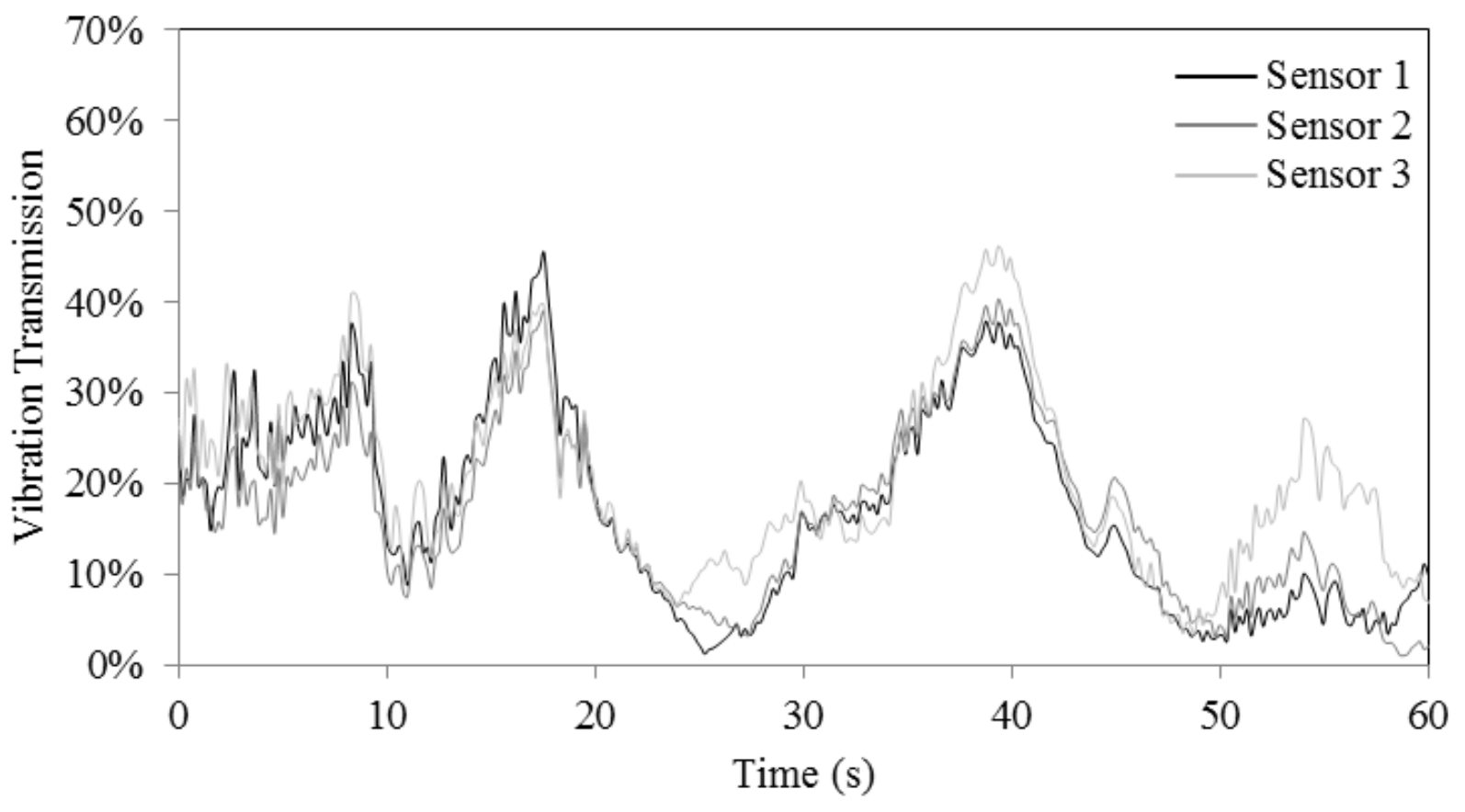


Figure 17: Percentage of vibration transmission between Floor Levels 1 and 2 along an exterior cladding panel in the Charles Institute research facility.

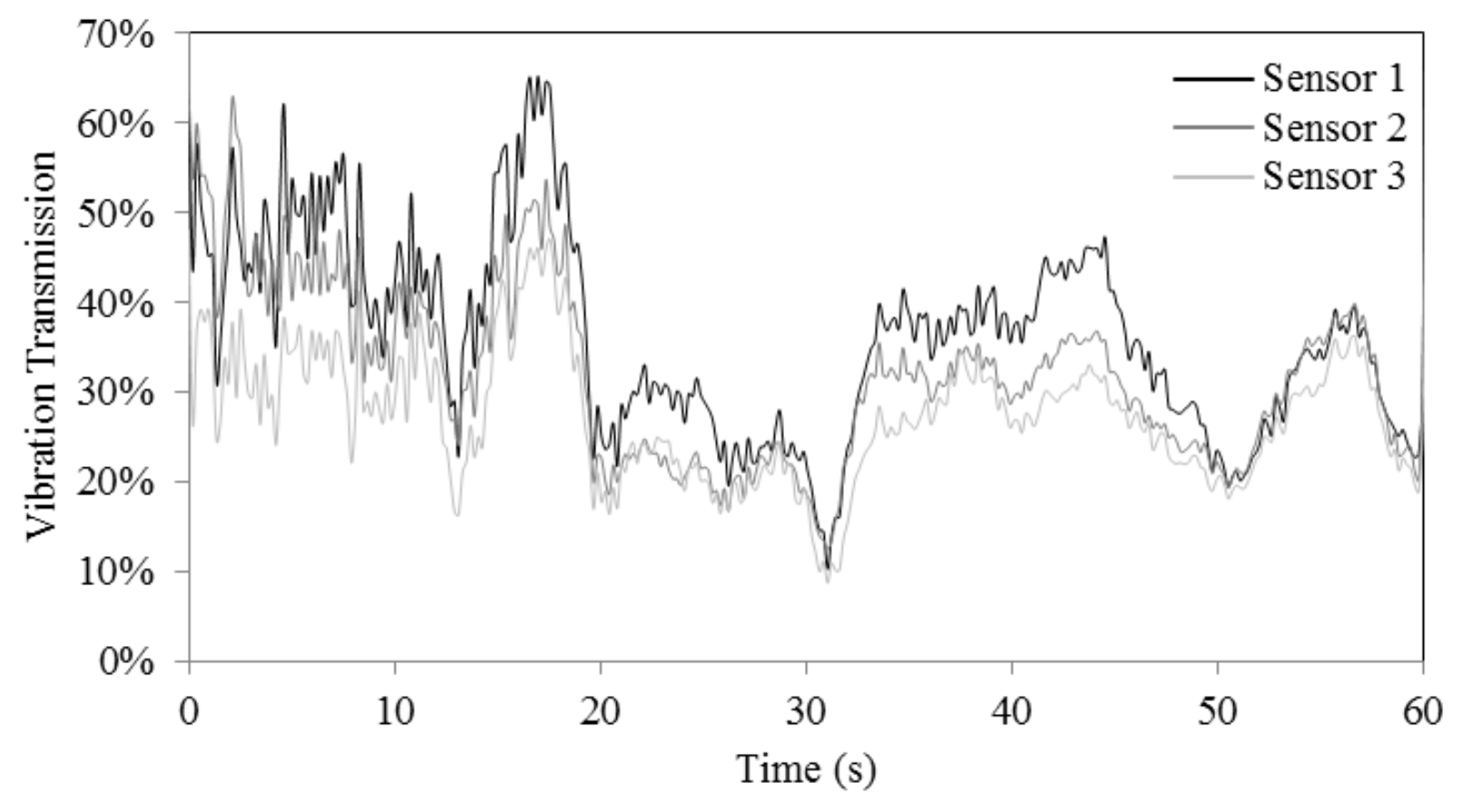

Figure 18: Percentage of vibration transmission between Floor Levels 1 and 2 along an internal partition in the Charles Institute research facility. 